\title{
Necessity and Production of Medicinal Plants under Controlled Environments
}

\author{
Sayed M. A. ZobaYeD*, Fawzia Afreen and Toyoki KozaI \\ Department of Bioproduction Sciences, Faculty of Horticulture, Chiba University, \\ Matsudo, Chiba 271-8510, Japan
}

(Received June 30, 2005)

\begin{abstract}
The estimated value of the worldwide sales of plant-based medicines exceeds $\$ 15$ billion in the year 2004. The international trade of plant-based medicines is becoming a major strength in the global economy and the demand is increasing in both developing and industrialized nations. However, the explosive growth of the trade of plant-based medicines has been accompanied by issues of quality, consistency and efficacy and leading to serious health problems associated with traditional field-grown plants or wild-harvest. This article discusses the problems associated with the cultivation, harvesting and process of medicinal plants for the production of phytopharmaceuticals. We suggest that it is necessary to ensure the safety and efficacy of plant-based medicines and to protect the genetic diversity of medicinal plants. An alternative is the cultivation of medicinal plants under controlled environments, which allows the precise control of optimized environmental conditions with maximum biomass and medicinal metabolites production and ensures the plants free from biotic and abiotic contaminations with consistent biochemical profiles. The controlled environment technology also ensures application of specific, controlled environment stresses that can optimize the production of medicinal metabolites by inducing natural biochemical changes in plants.
\end{abstract}

Keywords : controlled environment, Echinacea, plant-based medicines, phytopharmaceutical, variability in medicinal plant

\section{INTRODUCTION}

The therapeutic use of plants goes back to the dawn of time and is found in almost every civilization in the earth. Currently the worldwide trade of plant-based medicines has exceeded $\$ 15$ billion and is becoming a major force in the global economy. On the basis of current trends in market research data, it has been predicted that trades of plant-based medicines will continue to increase (Barnes, 2003). However, this explosive growth of the consumption of plant-based medicines has been accompanied by issues of quality and consistency, compromising the safety and efficacy leading to serious health problems (Zobayed et al., 2004a,b). These issues include the adulteration and contamination with misidentified plant species, contamination with plant and soil born microbial and environmental pollutants leading to wide variation of the concentration of medicinal metabolites in the plant tissues. These problems are mainly associated with traditional field- or wildharvest plants since plant species are complex biological systems with varying capabilities for absorption of nutrients and contaminants from the environment.

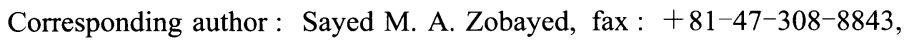

e-mail : zobayed@restaff.chiba-u.jp

e-mail : Dr.Zobayed@plant.org 
With the increasing demand of plant-based medicines, and increasing concern regarding the safety issues, in many countries, the future is set to improve their quality and in near future manufacturers will need to meet standards or have to remove their products from the market. Therefore, it is essential to develop a research scheme to overcome these issues and to ensure the production of consistent, quality plant-based medicines.

Recent advances in the area of controlled environment offer some possibility for the development of long-term solutions to these problems, and ensure the mass production of consistent, standardized plant-based medicines. In this article we discuss the issues of plant-based medicines and suggest the controlled environment technology as an alternative way to solve these issues.

\section{THE ISSUES WITH PLANT BASED MEDICINES}

\section{Biotic and abiotic contamination}

Bacterial and fungal contaminations as well as insect and pest invasion in plants can be a potential threat to both quality and quantity of medicinal metabolites in many plant species. For example, Septoria infection was shown to reduce the concentration of glycoside, an active constituent in Digitalis lanata (Bernath, 1986). Phytophtora infestans can cause a loss of $16-20 \%$ in the steroid glycol-alkaloid content of Solanum laciniatum (Mathe and Foldesi, 1965). Under field, greenhouse and plant tissue culture conditions about $10 \%$ of the active alkaloids accumulated in Papaver sp. decomposed within hours of exposure to Dendryphion penicillatum or Alternaria alternata (Bernath, 1986).

Another important aspect is that the plant-based medicine could be a direct threat to human health. Medicinal plants are commonly prepared as whole tissues and may remain unwashed to preserve metabolites in glands that would be ruptured in cleaning. Therefore, the consumer is frequently ingesting soil, bacteria, fungi and environmental pollutants along with the medicine. Moreover, the use of specific pesticides for the control of insect/pest raises serious question about these "natural" and "safe" products (Choffe et al., 2000). Heavy metals have recently been quantified and identified in some of the herbal preparations. For example, in December 1998, analysis of Niuhuang, Xhiaoyanwan, or Ansenpunaw products by Health Canada had quantified levels of mercury sufficient to pose a high risk of mercury poisoning to either adults or children (Murch et al., 2000). In the products of Golden seal, Liu et al. (2003) recently showed the various quantities of nickels.

\section{Adulteration with misidentified plant species and weeds}

Substitution of one plant species for another can have serious implications for human health. It is evident from the literature that the nine species of Echinacea are often created confusion to the growers due to indistinguishable morphological differences. For example, E. angustifolia has been consistently referred as E. pallida (Baskin et al., 1994). The presence of Parthenium integrifolium (a weed from compositae family) has been reported in commercial $E$. purpurea products (Bauer, 1998; Hobbs, 1989). Commercial preparations of E. angustifolia and E. purpurea have been found to contain Echinacea pallida as a result of misidentification due to similar plant morphology (Small and Catling, 1999; Hobbs, 1989). It should be mentioned that the profile of active constituents in E. pallida is different from that of either E. angustifolia or E. purpurea (Hobbs, 1989). The misidentification of species can have serious consequences since the species contain different chemical profiles (Schulthess et al., 1991).

\section{Variability in medicinal plant products}

The wide variation in the quality of various brands of products in the market has often been reported and became a considerable concern for consumers, manufacturers and regulatory bodies. Field-grown medicinal plant is subject to a number of sources of variation and as such the content of its active chemical constituents can be altered substantially. Possible reasons for this wide 
variation of medicinal metabolites may be the environmental, agronomical, and genetic variabilities as well as pollution and invasion by fungus, bacteria, viruses and insects. These extreme variations of medicinal metabolites in plant-based medicines pose challenges for conducting analytical and clinical research to ensure safety and efficacy. For example, in St. John's wort, a wide variation of hypericin and pseudohypericin contents in the commercially prepared capsules undermines its prospect and raises a serious safety concern. In 1998, the Consumer Safety Symposium on Dietary Supplements and Herbs reported a 17-fold difference in the concentration of 'active' constituents in commercial preparations of St. John's wort. Southwell and Bourke (2001) recently reported that the contents of hypericin and pseudohypericin in leaves of St. John's wort varied up to 50-fold in summer- and winter-grown plants. Bauer (1999) described a wide variation in the contents of cichoric acid and dodeca-2E, 4E, 8Z, 10E, Z-tetraenoic acid-isobutylamide in the aerial parts of Echinacea purpurea collected in the months of July, August and September. Possible reasons for these wide variations are discussed below.

Genetic variability

Until now, production of plant-based medicines is largely dependent on the wild collection and field-grown plants. Wild populations of medicinal plants typically have a high degree of genetic variability and therefore represent a substantial part of the available genetic diversity in the world (Bernath, 1986). Figure 1 shows the variation of total hypericin concentration in the leaf tissues of randomly selected 30 different seed-derived plants. In this study, plants were grown under a controlled environment and all the environmental factors $\left(\mathrm{CO}_{2}\right.$ concentration $1,000 \mu \mathrm{mol} \mathrm{mol}{ }^{-1}$; temperature $25^{\circ} \mathrm{C}$, photoperiod $16 \mathrm{~h}$, PPF $250 \mu \mathrm{mol} \mathrm{m}^{-2} \mathrm{~s}^{-1}$; relative humidity $65 \%$, nutrient concentration; half strength Hyponex solution; Hyponex, N:P:K; 6:10:5, Hyponex Corp., Ltd., Osaka, Japan) and irrigation frequency (once every 2 days) were precisely controlled to minimize their effects on bioactive constituents. However, results showed that a significant variation of the total hypericin concentration in the leaf tissues of 30 seed derived plants (Fig. 1). This indicating the genetic materials in different seed derived plants responsible to synthesize the secondary metabolites is in some extent different from each other. Therefore, it is essential to select a superior germplasm with optimized medicinal metabolite concentration and growth. This potential can provide the

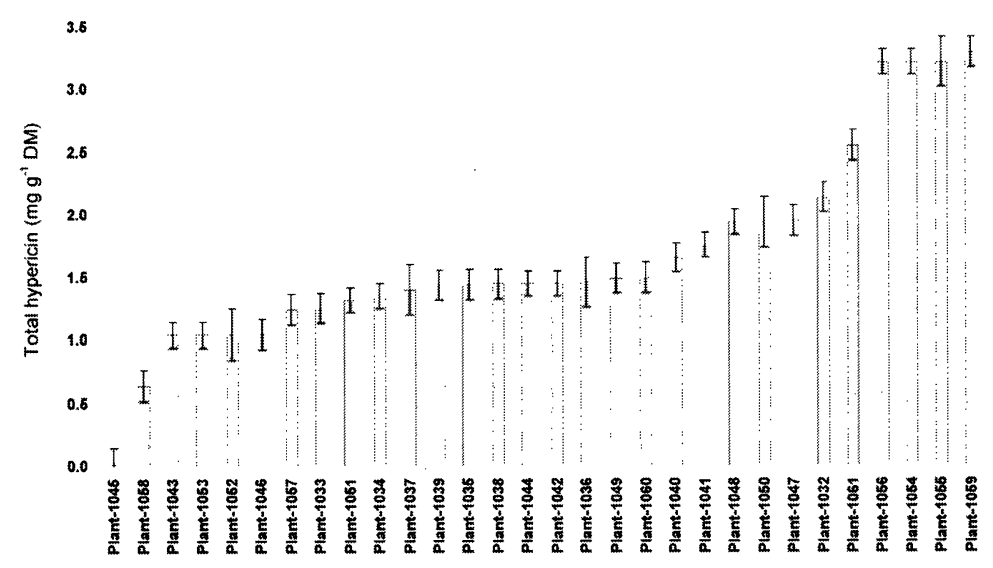

Fig. 1 Total hypericin (hypericin + pseudohypericin) concentration in the leaf tissues of individual seedderived plants (germplasm) of St. John's wort plants grown under controlled environments with elevated $\mathrm{CO}_{2}$ concentrations $\left(1,500 \mu \mathrm{mol} \mathrm{mol}^{-1}\right)$ and $250 \mu \mathrm{mol} \mathrm{m}^{-2} \mathrm{~s}^{-1}$ photosynthetic photon flux $(16 \mathrm{~h}$ photoperiod) at $27^{\circ} \mathrm{C}$ temperature. Seeds were collected from Murakami Seed Co., Ltd. (Ibaraki, Japan). Each bar represents a mean $\pm \mathrm{SE}$ of 5 leaf samples collected from different location of a single plant. The extraction, isolation and chemical analysis methods for hyperforin, pseudohypericin and pseudohypericin were modified from the method described by Zobayed et al. (2004a). 
basis for the improvement of the plant-based medicine industry and can lead to the development of superior cultivars for specific phyto-medicinal crops.

\section{Growing conditions}

The synthesis of the basic skeletons for active secondary metabolites is dependent on the carbon assimilated during photosynthesis. Therefore, the photoperiod (Zobayed et al., 2005), light intensity (Mosaleeyanon et al., 2005), and spectrum quality (Afreen et al., 2005) of the available light have been shown to influence the medicinal concentration. Similarly, warm weather conditions have shown to favor the synthesis of secondary metabolites while rainy weather can inhibit alkaloid production in many species (Bernath, 1986). As well, the availability of nutrients can profoundly affects chemical composition of medicinal plants (Sato et al., 2004). The plant species Atropa belladonna has shown to accumulate $1.3 \%$ of active alkaloid when grown in the Crimean Peninsula and only $0.3 \%$ when grown in Leningrad (Waller and Nowacki, 1978). These results indicate the necessity of growing medicinal plants under controlled environments to achieve a uniform, consistent plant-based medicine production.

\section{Post harvest handling and processing practices}

Harvesting and post-harvest handling including drying and storage of plant materials are other sources of inconsistency in its medicinal concentrations. Field-grown plant material is usually harvested only once a year; for example, June 24 is known as the harvesting date for St. John's wort plants. Most of the medicinal herbs are harvested during summer or autumn and this requires a complex system of purchase, post-harvest handling, import and transport of the raw plant materials, thereby, compromising the quality of the finished product due to inappropriate post-harvest and handling practices. Since drying generally involves heating, therefore, an inappropriate drying method can result in the evaporation of the volatile compounds from the material (Wijesekera, 1993). The concentration of the alkylamides and cichoric acid in Echinacea plants are largely dependant on temperature, light and moisture (Wijesekera, 1993). In addition, the alkamides found in Echinacea purpurea roots and aerial parts are known to be very unstable. Prolonged storage for 64 weeks at $24^{\circ} \mathrm{C}$ reduced the alkamides levels by over $80 \%$ in Echinacea purpurea while significant reduction in its level was also observed at storage temperature of $-18^{\circ} \mathrm{C}$ ( Perry et al., 1999). Similarly, the drying method significantly affected the alkamides level in dried roots and leaves and caffeic acid derivatives in the flowers of Echinacea purpurea (Kim et al., 2000a; Kim et al., $2000 \mathrm{~b}$ ). The concentration of echinicosides in the roots of Echinacea angustifolia decreased by $45 \%$ at $60{ }^{\circ} \mathrm{C}$ drying temperature compared with freshly plant materials (Kabganian et al., 2002). As a result, most of the herbal medicines will have much lower levels of biologically active alkamides than were present in the freshly harvested materials.

\section{Consumer frauds}

As most of the medicinal plants are still collected from wild, the elements of consumer fraud cannot be eliminated. In the absence of strict legislation for the characterization of the medicinally active components, it is very difficult to assess the degree, frequency and severity of the potential frauds. There is an urgent need to develop such technologies that can help regulate the herbal industry for ensuring safety of the consumer health. Practice of production of medicinal plants under controlled environment can minimize the unintentional consumer frauds.

\section{Extinction of wild population}

Concerns have arisen regarding the vulnerability of wild populations of medicinal plants due to over-harvest and extinction. More than 2,000 species of medicinal plants worldwide are currently under threat to be endangered. Goldenseal, for example, is listed in the Convention on International Trade in Endangered Species of Wild Fauna and Flora (CITES). Therefore, there is an immediate need for the development of new technologies for the conservation, characterization, and mass-production of medicinal plant species. 


\section{ALTERNATIVE APPROACH: CULTIVATION UNDER CONTROLLED ENVIRONMENTS}

To ensure the safety and efficacy of plant-based medicines and to ensure the protection of genetic diversity of medicinal plants, an alternative is the cultivation of plants in the agricultural lands or greenhouse. However, in the open field or greenhouse, it is difficult to grow plants free from pollutions, seasonal variations of temperature, light, UV, rainfall and others environmental factors. As mentioned earlier, all of these factors can influence the medicinal metabolite concentration. Moreover, in the conventional agriculture and horticulture, as a result of decades of high application of pesticide herbicides, insecticides, fungicides and fertilizer, the environment has already been degraded, causing serious damage to the structure and function of ecosystems even threatening the existence and development of the wild plant population. Moreover, growing medicinal plants in such an environment will also raise questions for the safety of human health. In the open filed or greenhouse, random crossing and mutation make it unable to get a consistent and variation-free medicinal plant production.

Therefore, we need to develop a new technology to ensure the safety of plant based medicines and maximize biomass and medicinal metabolites production by altering the agricultural techniques and more importantly to save the earth from hazardous pollutions. Consequently, the basic requirement for the proposed new technique of plant production should be a) minimize the consumption of resources, b) minimize the release of environmental pollutants, c) biotic and abiotic contamination free, d) optimized controlled environments with artificial light and e) achieve high production (Kozai et al., 2000).

Recently, Kozai et al. (1999) have developed a new concept for the production of plants in a closed system with contaminant free, quality biomass with desirable requirements. A similar system can be used for the production of medicinal plants, where a culture room containing many small trays or pots with thousands of plants on multi culture shelves with artificial light (Figs. 2, 3 and 4). The system should allow an automated nutrient supply system, multi-day programming and environmental control of photoperiod, temperature, relative humidity, light intensity, light quality and $\mathrm{CO}_{2}$ enrichment facility.

The specific advantages of this technology as an alternative approach for production of medicinal plants are:

1) Mass production with control over the quantity of plant materials and the time of delivery;

2) Independence from environmental, seasonal, geographical, and political limitations;

3) Optimized, controlled air temperature, relative humidity, $\mathrm{CO}_{2}$ concentration and air current speed regardless of the outer environment;

4) Reduced usage of land and agriculture resources;

5) Maximize the growth and medicinal concentrations under controlled optimized environments;

6) Consistent quality production of medicinal plants can be achieved and global standardization of plant based medicine can be realized and achieved because the system operation is almost independent of the local weather;

7) When necessary, inhibition or promotion of flower development can be achieved by controlling photoperiod, air temperature and light quality to improve the quality of medicinal plants;

8) Production period can be significantly reduced;

9) Biochemical characterization of active ingredients of a specific medicinal plants can be achieved universally;

10) Selection of individual, superior clones and genetic improvement is possible through 

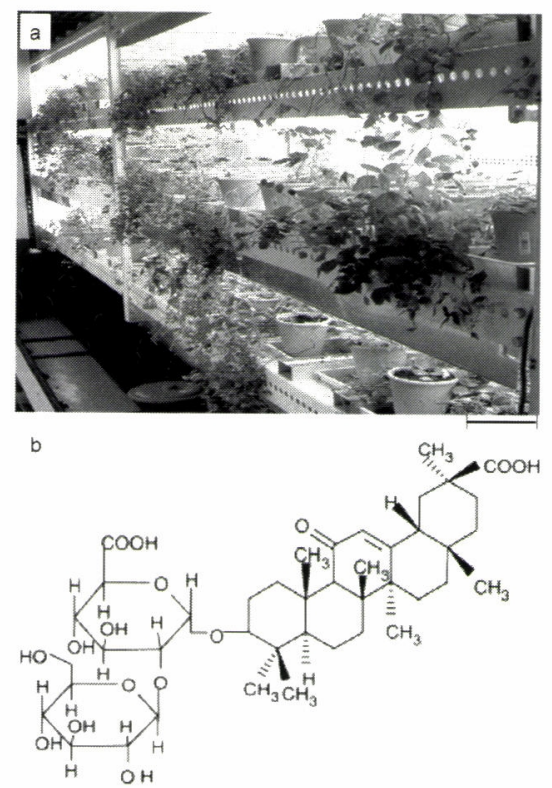

Fig. 2 a) Controlled environment production of Glycyrrhiza uralensis (bar $=7 \mathrm{~cm}$ ); b) chemical structure of Glycyrrhizin, the active constituent of Glycyrrhiza uralensis.
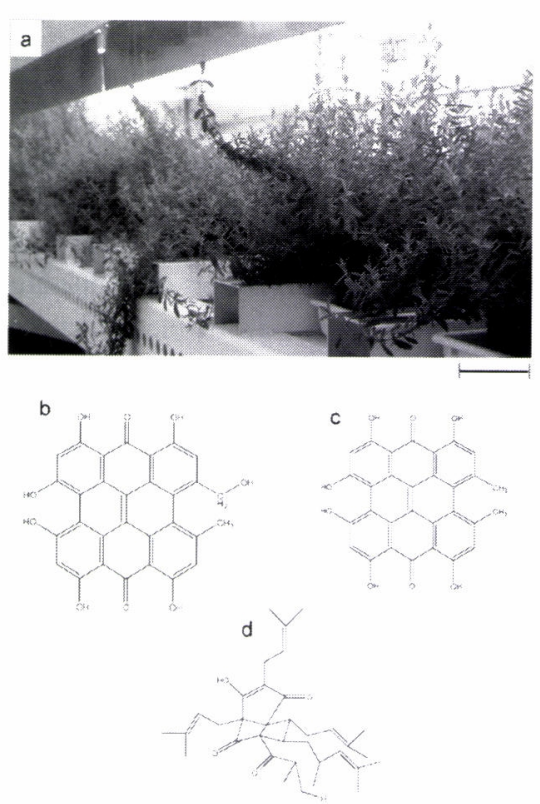

Fig. 3 a) Controlled environment production of St. John's wort plants $(\mathrm{bar}=6 \mathrm{~cm})$; b-d) chemical structures of major bioactive constituents of St. John's wort: b) hypericin, c) pseudohypericin and d) hyperforin.

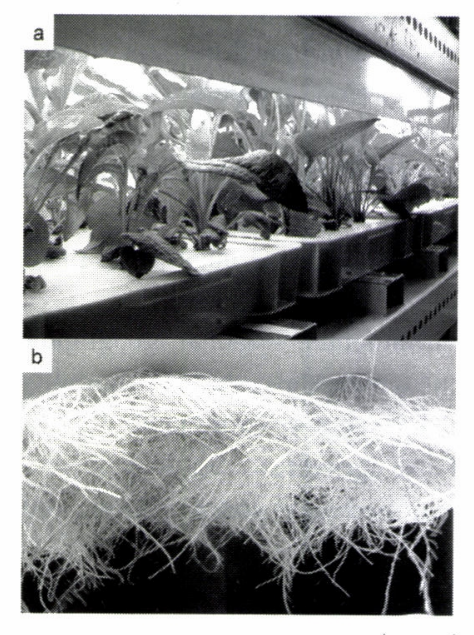

Fig. 4 Controlled environment production of Echinacea purpuria: a) hydroponic system with 50-days old plants; b) root production $(\mathrm{bar}=10 \mathrm{~cm})$.

biotechnology;

11) Long-term conservation of superior medicinal plant germplasm is feasible and selected superior germplasm can be propagated and grown with minimum time and labour; 


\section{MEDICINAL PLANTS UNDER CONTROLLED ENVIRONMENTS}

12) Insects, pest and pathogenic microorganisms can easily be prevented from entering the system and thus no need to use pesticide, fungicide, herbicide etc., moreover, unused fertilizer can be recycled and thus minimise the environmental pollution.

A step by step procedure for the development of superior and value-added plants for the production of consistent and high quality plant based medicine and for the standardization of the concentration of a desired bioactive compound is proposed in Fig. 5. A single (or multiple) germplasm need to be selected as almost all the medicinal plant species are currently collected from wild. After the completion of the screening process for the superior germplasm with high biomass and secondary metabolite production, plants need to be multiplied through clonal propagation (tissue culture) followed by optimization of the environmental and nutritional conditions after transplanting in a controlled environment condition (Fig. 5). This is the most complicated and prolonged procedure and an enormous research are required to accomplish these. Due to the responses to different physical, chemical and biotic elicitors, studies aiming to determine the effect of environmental conditions on concentrations of bioactive compounds in either a field or a greenhouse cannot be repeatable and remain inconclusive. As shown in Fig. 6 optimization of the environmental conditions such as light, temperature, photoperiod, spectral quality, relative humidity leading to the enhancement of the net photosynthetic rates followed by the maximization of biomass production under controlled environment is the next process to conduct. For many secondary metabolites, optimization of the environmental conditions for biomass production also simultaneously enhances the secondary metabolite production. For example, Mosaleeyanon et al. (2005) established a linear relationship between net photosynthetic rates of the leaves and the total hypericin content in the leaf tissues. However, for many plant species, maximization of the secondary metabolite production could be a major challenge and may not be directly related to the production of

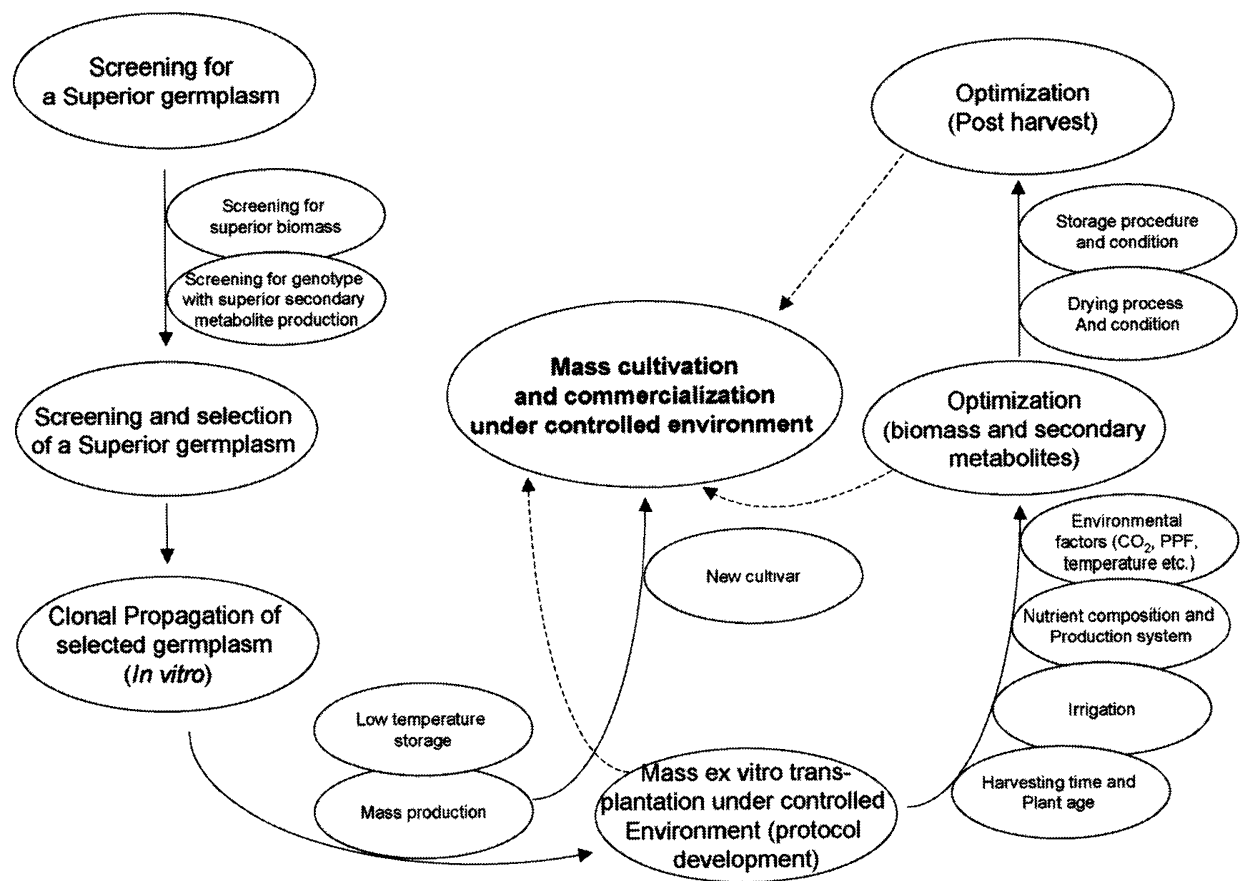

Fig. 5 A step by step procedure for the production of medicinal plants under controlled environment. A straight line arrow indicates a next step of the process and a broken line arrow indicates to gather information. 


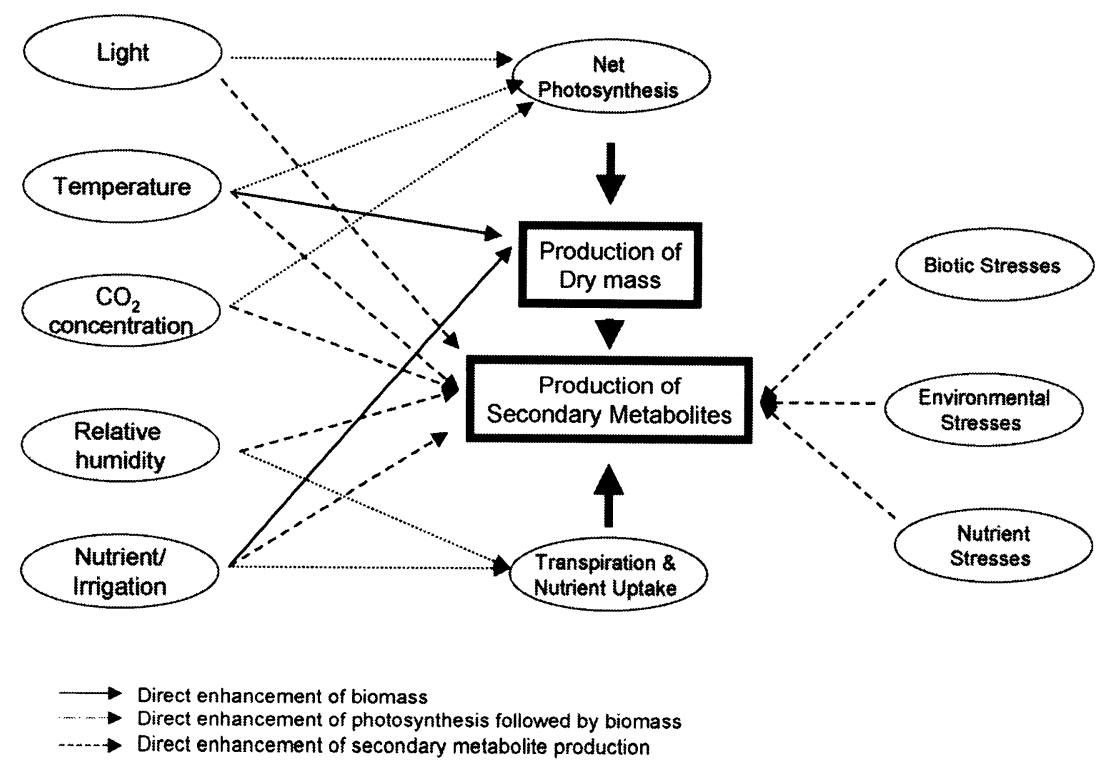

Fig. 6 Factors affecting the secondary metabolite production in medicinal plants.

carbon through the process of photosynthesis. In such a case, stress induced secondary metabolite production strategy can be adopted (Fig. 6) such as plants can be induced under biotic or abiotic stresses including environmental stresses (UV-B, Ozone, temperature, water stress etc.).

Final step is the commercial scale production under a controlled environment condition (Fig. 6). Recently, we have attempted to grow several valuable medicinal plants including Glycyrrhiza uralensis (Fig. 2a; Afreen et al., 2005) for the production of Glycyrrhizin (Fig. 2b), St. John's wort (Fig. 3a; Zobayed et al., 2005; Mosaleeyanon et al., 2005) for the production of hypericins and hyperforin (Fig. 3b-d) and Echinacea (Fig. 4) under a controlled environment with artificial light and enriched $\mathrm{CO}_{2}$ concentration. In our previous study, secondary metabolite concentration of St. John's wort plants grown under a controlled environment has been found to increase several fold compared with greenhouse (Zobayed and Saxena, 2004) and field production (Mosaleeyanon et al., 2005). In a recent study, Afreen et al. (2005) showed that Glycyrrhiza uralensis, an important medicinal plant, require only 3-6 months of growing period before harvest under a controlled environment with remarkably high glycyrrhizin concentration in the root tissues. Therefore, growing plants in a controlled environment seems to be a good alternative to wild collection which may have negative impact.

\section{CONCLUSIONS}

The principle prerequisite for the further development of high-quality phytopharmaceutical products is a consistent source of high-quality plant materials. The production of medicinal plants under controlled environments described in this article represents a significant advancement for phytopharmaceutical production. The use of such a controlled environment system for the production of medicinal plants has a potential to provide mass quantities of consistent, standardized and optimized plant materials free from biotic and abiotic contaminations. Selection, breeding and cloning of superior individual genotypes and the biochemical characterization of medicinally active constituents can be achieved and thus the applications of this technology are immense and further development has significant potential. 


\section{MEDICINAL PLANTS UNDER CONTROLLED ENVIRONMENTS}

The financial support of the Japan Society for the Promotion of Science and Technology (Special JSPS for North American and European Researcher) is gratefully acknowledged.

\section{REFERENCES}

Afreen, F., Zobayed, S. M. A., Kozai, T. 2005. Spectral quality and UV-B stress stimulate Glycyrrhizin concentration of Glycyrrhiza uralensis. Plant Physiol. Biochem. (in press).

Barnes, J. 2003. Quality, efficacy and safety of complementary medicines: fashions, facts and the future. Part I. Regulation and quality. Br. J. Clin. Pharmacol. 55: 226-233.

Baskin, J. M., Snyder, K. M., Baskin, C. C. 1994. Misapplied name of the purple coneflower in the ecological studies of John E. Weaver. Torr. Bot. Club 121: 73-75.

Bauer, R. 1999. Chemistry, analysis and immunological investigations of Echinacea phytopharmaceuticals. In "Immunomodulatory Agents from Plants". (ed. by Wagner H), Birkhauser Verlag, Basel, Boston, Berlin, pp 41-88.

Bauer, R. 1998. The Echinacea story-the scientific development of an herbal immunostimulant. In "Plants for Food and Medicine" (ed. by H.D.V. Prendergast, N.L. Etkin, D.R. Harris, P.J. Haughton), The Royal Botanic Gardens, Kew, UK, pp 317-332.

Bernath, J. 1986. Production ecology of secondary plant products. J. Herbs Spices Med. Plants. 1: 185-234.

Choffe, K. L., Murch, S. J., Saxena, P. K. 2000. Regeneration of Echinacea pupurea: Induction of root organogenesis from hypocotyls and cotyledon explants. Plant Cell Tiss. Org. Cult. 62: 227-234.

Consumers Safety Symposium on Dietary Supplements and Herbs. 1998. New Good Housekeeping Institute study finds drastic discrepancy in potencies of popular herbal supplement. Good Housekeeping Institute. New York, N.Y., March 2.

Hobbs, C. 1989. The Echinacea Handbook. (ed. by Miovich, M.), Eclectic Medical Publications, Portland, Oregon.

Kabganian R., Carrier, D.J., Sokhansanj S. 2002. Physical characteristics and drying rate of Echinacea root. Drying Tech. 20: $637-649$.

Kim, H. O., Durance, T. D., Scaman, C. H., Kitts, D. D. 2000a. Retention of alkamides in dried Echinacea purpurea. J. Agric. Food Chem. 48: 4187-4192.

Kim, H. O., Durance, T. D., Scaman, C. H., Kitts, D. D. 2000b. Retention of caffeic acid derivatives in dried Echinacea purpurea. J. Agric. Food Chem. 48: 4182-4186.

Kozai, T., Ohyama, K., Afreen, F., Zobayed, S. M. A. Kubota, C., Hoshi, T., Chun, C. $1999 . \quad$ Transplant production in closed systems with artificial lighting for solving global issues on environment conservation, food, resource and energy: 31-45. New Brunswick, NJ. CCEA, Rutgers University. Proc. ACESYS III Conf., 23 July.

Kozai, T., Kubota, C., Chun, C., Afreen, F., Ohyama, K. 2000. Necessity and concept of the closed transplant production system. In "Proceedings for the International Symposium on Transplant Production in Closed System" (ed. by Kubota, C., Chun, C.), Kluwer Academic Publisher, Dordrecht, the Netherlands, p 3-19.

Liu, C. Z., Murch, S. J., Jain, J. C., Saxena, P. K. 2003. Goldenseal (Hydrastis Canadensis L.): In vitro regeneration for germplasm conservation and elimination of heavy metal contamination. In Vitro Cell. Dev. Biol. Plant 40: 75-79.

Mathe, I., Foldesi, D. 1965. Az orvosi csucsor (Solanum laciniatum Ait.) Magy. Kulturfloraja 24. Akademiai Kiado, Budapest. 80 p.

Mosaleeyanon K., Zobayed S. M. A., Afreen F., Kozai T. 2005. Relationships between net photosynthetic rates and secondary metabolite concentrations in St. John's wort. Plant Sci. 169: 523-531.

Murch, S. J., Krishnaraj S., Saxena, P. K. 2000. Phytopharmaceuticals: Problems, Limitations and Solutions. Sci. Rev. Alt. Med. 4: 33-38.

Schulthess, B. H., Giger, E., Baumann, T. W. 1991. Echinacea: anatomy, phytochemical pattern, and germination of the achene. Planta Med. 57: 384-388.

Small, E., Catling, P. M. 1999. Canadian medicinal crops. NRC Research Press, Ottawa, p 46-52.

Perry, N. B., Klink, J. W. V., Burgess, E. J., Parmenter, G. A. 1999. Alkamides levels in Echinacea purpurea: Effect of processing, drying and storage. Planta Medica 66: 54-56.

Sato, S., Ikeda, H., Furukawa, H., Murata, Y., Tomoda, M. 2004. The effects of nutrient solution 


\section{S. M. A. ZOBAYED ET AL.}

concentration on Inorganic and Glycyrrhizin contents of Glycyrrhiza glabra Linn. Yakugaku Zasshi (Japanese Journal) 124: 705-709.

Southwell, I. A., Bourke, C. A. 2001. Seasonal variation in hypericin content of Hypericum perforatum L. (St. John's Wort). Phytochemistry 56: 437-441.

Waller, G. R., Nowacki, E. W. 1978. Alkaloid Biology and Metabolism in Plants. New York, NY, Plenum Press.

Wijesekera, R. O. B. 1993. Processing of medicinal plant derived preparations in developing countries: Prospects and prospectives. Acta Hortic. 332: 63-71.

Zobayed, S. M. A., Afreen, F., Kozai T. 2005. Temperature stress can alter the photosynthetic efficiency and secondary metabolite concentrations in St. John's wort. Plant Physiol. Biochem. 43: (in press).

Zobayed, S. M. A., Saxena, P. K. 2004. Production of St. John's wort plants under controlled environment for maximizing biomass and secondary metabolites. In Vitro Cell. Dev. Biol. Plant 40: 108-114.

Zobayed, S. M. A., Murch, S. J., Rupasinghe, H. P. V., Saxena, P. K. 2004a. In vitro production and chemical characterization of St. John's wort (Hypericum perforatum L. cv 'New Stem'). Plant Sci. 166: 333-340.

Zobayed, S. M. A., Murch, S. J., Saxena, P. K. 2004b. Elevated carbon supply altered hypericin and hyperforin contents of St. John's wort (Hypericum perforatum) grown in bioreactor. Plant Cell Tiss. Org. Cult. 75: 143-149. 